\title{
Discurso e mídia: construção de concepções da pessoa com deficiência intelectual em propagandas
}

\author{
Carla Maria de Schipper* \\ Denise Gabriel Witzel**
}

\section{Resumo}

Este trabalho foi concebido com o intuito de compreendermos o trabalho da linguagem com relação à construção de concepções de Deficiência Intelectual na contemporaneidade e a gênese discursiva dessas, a partir da análise do discurso de propagandas veiculadas por uma instituição de educação especial no período de 1980 a 2009. Para realizar esta ação, utilizou-se como base teórica a Análise do Discurso (AD) de perspectiva francesa, sobretudo os conceitos de interdiscurso, memória e heterogeneidade. Anteriormente à análise, necessário se fez apresentar algumas noçóes basilares da $\mathrm{AD}$ e as diversas concepções de deficiência que surgiram ao longo da história. O material de análise é composto por cinco textos publicitários publicados em uma revista especializada que representa instituiçóes voltadas ao atendimento da pessoa com deficiência intelectual e uma propaganda para arrecadação de recursos. $\mathrm{O}$ resgate da memória discursiva, considerando as condiçóes sócio-históricas de produção, permitiu dar visibilidade às diferentes posiçôes do sujeito Deficiente Intelectual na sociedade em cada momento relatado. Nos discursos enunciados, observaram-se estratégias de internalização de papéis sociais voltados à inclusão educacional, mas, no interdiscurso, revelaram-se discursos outros que sedimentam antigos paradigmas da medicalização e do trabalho como missão.

Palavras-chave: Deficiência Intelectual; Discurso; Heterogeneidade.

* Mestranda em Educação pela Universidade Estadual do Centro-Oeste. Guarapuava, Paraná, Brasil.

** Professora doutora da Universidade Estadual do Centro-Oeste. Guarapuava, Paraná, Brasil. 


\section{Discourse and media: construction of concepts about person with intellectual disability in advertisements}

\section{Abstract}

This study was designed in order to understand language work respecting the construction of conceptions about Intellectual Disabilities in the contemporary discourse and their discursive genesis. The basis of the discourse analysis were advertisements published by an institution of special education in the period of 1980 to 2009. To perform this action, the Analysis of Discourse (AD) from French perspective, especially the concepts of interdiscours, memory and heterogeneity, was used as a theoretical basis. Prior to analyzing, presenting some basic concepts of $\mathrm{AD}$ and the various conceptions of disability that have arisen throughout history was proven necessary. The Material for analysis is composed of five advertising texts published on a magazine that represents institutions devoted to the care of people with intellectual disabilities and an advertisement to raise funds. The recovery of memory discourse, considering the socio-historical condition of production of discourse, has given visibility to the different places occupied by the person with intellectual disability in the society in each time reported. At the speeches of subject enunciators, attempts to internalize the social roles focused on educational inclusion have been observed, but at the interdiscours, they proved to be voices that exceeded sediment paradigm of medicalization and work as mission.

Keywords: Intellectual Disabilities; Discourse; Heterogeneity.

\section{Introdução}

Este estudo ocupa-se de uma revisão dos construtos sócio-históricos das ideias de deficiência, analisando o discurso de propagandas com a finalidade de compreender a natureza das concepçóes sobre o Deficiente Intelectual na atualidade.

A busca por esta compreensão se dará pelo viés interpretativo da Análise do Discurso de perspectiva francesa, teoria que permitirá ultrapassar os limites estruturais dos textos e dar relevo ao papel da memória na produção e reproduçáo de sentidos sobre a deficiência, bem como à história inscrita nas práticas discursivas que, além de forjar a identidade do deficiente, permite observar os desdobramentos, os deslocamentos ou a sedimentação de sentidos tomados como "evidentes" no senso comum, concordando com Piccolo e Mendes (2012, p. 31) que é preciso "destacar suas variaçôes temporais, posto que modos distintos de produção social engendrem distintas silhuetas do que é visto como diferente".

Entre o passado e o presente, entre as antigas e as novas concepçôes, perseguiremos os efeitos de sentido que apontam para a necessidade de se entender o discurso como um acontecimento que tenciona a memória e o esquecimento. 
Para tanto, elegemos como material de análise cinco peças publicitárias veiculadas em revista impressa de circulação nacional coordenada pela Federação Nacional das APAE's (Associação de Pais e Amigos dos Excepcionais) com temas voltados para o atendimento social e educacional da pessoa com deficiência e um folder de campanha publicitária para arrecadação de recursos. A escolha das peças não se deu de forma aleatória, estas inserem-se em dois momentos distintos da construção da conceituação da deficiência no âmbito educacional: o movimento da integração que tem seu ápice no Brasil a partir de 1980 e o movimento de inclusão pós Declaração Mundial de Educação para Todos (1990) e Salamanca (1994). Embora as peças remetam a momentos distintos, os atravessamentos revelam práticas de atendimento ora assistencial, ora integrador; outros, ainda, são reveladores do paradigma da inclusão.

Quem é o sujeito com deficiência intelectual aos olhos das propagandas? Quais são as concepções que sustentam tal identidade? Que outros discursos, entrelaçados em redes interdiscursivas, possibilitam os dizeres e as imagens nessas publicidades? Eis as questóes que norteiam as reflexões e impóem alguns esclarecimentos sobre os conceitos de discurso, memória e interdiscurso, além da retomada das concepçôes de deficiência proclamadas pela sociedade e registrada pela/na história.

O retorno aos discursos outros - exteriores e anteriores aos textos publicitários selecionados - será, portanto, a base sobre a qual trataremos da rede interdiscursiva que constitui o imaginário e o sujeito com deficiências, tomando o discurso como efeito de sentido.

\section{Discurso, interdiscurso e memória}

A palavra discurso, etimologicamente, tem em si a ideia de curso, de percurso, de correr por, de movimento. O discurso é assim palavra em movimento, prática de linguagem: com o estudo do discurso observa-se o homem falando. (ORLANDI, 1999, p. 15).

Essa afirmação, considerada no âmbito da Análise do Discurso (AD) de perspectiva francesa, aponta para a compreensão da língua "fazendo sentido", enquanto trabalho simbólico (ORLANDI, 1999). Isso significa que a AD não trabalha com a lingua fechada nela mesma, vista como um sistema abstrato, mas com o discurso, tomado como um objeto sócio-histórico em que o linguístico figura como pressuposto. Ancorados na tríplice aliança - linguística, história e psicanálise -, os estudos da AD articulam necessariamente língua, sujeito e história.

Em tal perspectiva teórica, o que importa é o funcionamento discursivo da linguagem e a mobilidade dos discursos, resultado das transformaçóes históricas. Importante destacar que essa mobilidade e essas transformaçóes interferem nos sentidos das palavras (e mesmo das imagens), pois um ou outro sentido depende dos lugares sociais, ideológicos e históricos ocupados pelos enunciadores.

Para explicar melhor o que significa discurso, vale sublinhar o que afirma Maldidier (2003, p. 21): o discurso na $\mathrm{AD}$ é concebido "como um conceito que não se confunde nem com o discurso empírico sustentado por um sujeito nem com o texto, 
um conceito que estoura qualquer concepção comunicacional da linguagem”. Analisá -lo é perseguir os processos de apreensão, produção e circulação de sentidos, considerando a possibilidade e a necessidade de interpretá-los para além do claustro do texto; é entender a língua como materialidade dos discursos, atualizada diferentemente em distintos processos discursivos; é, ainda, partir do pressuposto que o sentido sempre pode ser outro.

No interior dessas constataçôes, assumem especial relevância os conceitos de interdiscurso e memória discursiva. Trata-se, fundamentalmente, de formulações orientadas pela ideia de heterogeneidade, na medida em que parte-se do princípio de que há, incontestavelmente, uma alteridade/exterioridade conflitante inerente a qualquer produção discursiva. $\mathrm{O}$ modo como a memória é trabalhada na $\mathrm{AD}$ implica considerar que os enunciados possuem uma existência histórica e que os discursos são (re)produzidos em uma rede que implica lembranças ou esquecimentos, repetiçóes ou silenciamentos de outros discursos. Por isso, nem sempre ela é localizável na linearidade do discurso; é necessário acionar a relação entre o interdiscurso - dimensão vertical, lugar de constituição do pré-construído - e o intradiscurso - dimensão horizontal, lugar do fio do discurso, dos encaixes sintáticos. O trabalho do analista consiste, portanto, em localizar os vestígios da memória que possibilitam a produçáo (e a apreensão) dos sentidos, já que esta " é a condição da produção e da interpretação dos discursos” (PÊCHEUX, 2011, p. 102).

Para tratar do "discurso outro" toda análise visa remeter o texto a uma rede de formulaçôes discursivas. Rede de muitos nós e vácuos, infinitamente tramada de modo que não é possível identificar com precisão a origem dos sentidos de certo texto, pois seu discurso é construído por múltiplos momentos da história e diferentes lugares sociais, enredados no interior da formação discursiva.

Vê-se, assim, que a produção de um discurso envolve sujeitos, circunstâncias e a rede de memória acionada nesta produção/leitura. Há um saber anterior, inscrito na memória, que sustenta o dizer naquilo que já foi dito, reconstruindo o discurso. Os traços sociais e históricos que estão no espaço da memória, materializados através dos fatos sociais, momentos culturais, eventos midiáticos e outros discursos precedentes, interferem na construção de sentidos. Assim a memória,

é necessariamente um espaço móvel de divisões, de disjunçốes, de deslocamentos e de retomadas, de conflitos de regularização. Um espaço de desdobramentos, réplicas, polêmicas e contra-discursos. (PECHÊUX, 1999, p. 56).

Há ainda acontecimentos históricos e políticos que podem produzir silenciamentos e ocultação de palavras graças aos processos de censura a que são submetidos alguns grupos sociais. Processo similar ocorre com aqueles que, dominados pelas Instituiçóes e o Poder, são privados do seu direito de expressáo. A posse do discurso e dos sentidos pelo poder econômico e político podem provocar silenciamentos e até esquecimentos, "para que surjam novos sentidos mas também esquecer apagando os novos sentidos que já foram possíveis mas foram estancados em um processo histórico-político silenciador. São sentidos que são evitados, re-significados" (ORLANDI, 1999, p. 62). 
A memória ressoa lembranças, dispersóes e esquecimentos e possui um papel imperioso na formaçâo discursiva. Nas palavras de Pêcheux, ao se analisar a memória no discurso, é preciso entender essa memória como aquilo que "face a um texto que surge como acontecimento a ler, vem restabelecer os 'implícitos' (...) de que sua leitura necessita: a condição do legível em relação ao próprio legível” (PÊCHEUX, 1999, p. 52). Daí ela ser constitutiva do dizer, imbricada no domínio das formulaçóes. Por isso, é o retorno aos acontecimentos históricos, a reatualização de redes de memória que propiciam a compreensão do movimento dos sentidos evocados na constituição do discurso presente.

Necessário se faz, doravante, refazer o percurso histórico das concepções de deficiência presentes na sociedade, para, enfim, interpretar as concepçôes sobre deficiência intelectual, marcadas no imaginário da sociedade contemporânea e materializadas nas propagandas que compóem nosso conjunto de análise.

É a luz dessas concepções que será possível dar visibilidade às transformações do conceito de deficiência intelectual no percurso histórico que, inevitavelmente, constituem os discursos da atualidade, como as constantes discriminaçóes e sentimento de comoção que atingem os DI. Ao serem analisadas as peças publicitárias mais à frente, buscar-se-á apreender os múltiplos e diferentes discursos que falam da/ sobre a deficiência, advindos de outros sujeitos inscritos em determinadas formaçóes discursivas, em conformidade com o espaço social por ele ocupado, produzindo certos sentidos e não outros.

\section{Breve história do conceito de deficiência intelectual}

Para elucidar a forma como a sociedade atual compreende a deficiência, é necessário conhecer as diferentes concepçóes proclamadas pela sociedade em determinados momentos sociais, políticos, culturais e científicos que foram registrados pela história. Esses registros são descritos em uma ordem de acordo com a jornada humana, embora esses julgamentos culturais lineares da deficiência apontem recidivas, fato que será demonstrando na análise da peças publicitárias e que Piccolo e Mendes (2012), de antemão, observaram acerca da teatralizaçáo da deficiência que adentrou a idade moderna através dos Freak Shows, espetáculos teatrais pagos visando a "mercantilização das diferenças" (Ibid, p. 37).

Mas de qualquer forma, é possível descortinar a imagem construída pela sociedade acerca da Deficiência Intelectual desde os primeiros registros, traçando a conceituação da deficiência através dos movimentos sociais e culturais.

Alguns destes registros remontam ao período clássico, quando em Esparta e Atenas portadores de deficiências "eram considerados sub-humanos, sua eliminação e abandono estavam em consonância com os ideais atléticos/estéticos e a potência dos guerreiros" (CECCIM, 1997, p. 23). Dessa forma, por serem considerados inferiores, a eliminação era natural e tinha uma forte marca cultural de manutenção de uma construção social de mente e corpo ideal que se perpetuava através da prática do extermínio, abandono ou a teatralizaçáo: 
Desde o Egito imperial se notava a existência de alguns espetáculos envolvendo corpos definidos como bizarros e grotescos a fim de entreter o público, dentre os quais se encontravam os aleijados, cegos, surdos, dentre outros, hoje rebatizados de deficientes físicos e sensoriais. (PICCOLO; MENDES, 2012, p. 32).

Na Idade Média, sob a influência do cristianismo, o deficiente passa a ter alma, no entanto, uma alma deformada (Ibid, 2012, p.35). Tolerava-se a deficiência como princípio de altruísmo: "por serem merecedores de caridade, deveriam ficar segregadas, recebendo moradia e alimentação" (RIBEIRO, 2003, p. 43).

A deficiência era compreendida como uma aflição natural pelos pecados, cabendo, assim, à igreja cuidar da redençáo destes. O DI seria um pecador e sua condiçấo, retrato de sua culpa:

A própria religiāo, com toda a sua força cultural, ao colocar o homem como "imagem e semelhança de Deus", ser perfeito, inculcava a ideia da condição humana como incluindo perfeição física e mental e não sendo "parecidos com Deus" os portadores de deficiência (ou imperfeiçóes) eram postos à margem da condição humana. (MAZZOTTA, 2001, p. 16).

As intensas mudanças culturais, sociais e econômicas motivadas pelo renascimento e a consequente diminuição da concepção teocêntrica trouxeram alteraçôes na concepçáo da deficiência. As novas compreensóes passaram, assim, pelos estudos de médicos que buscavam esclarecer as origens da deficiência. Dessa forma,

o médico passa a se transformar em novo árbitro do destino do deficiente, julga, salva e condena se valendo de um corpo de conhecimentos que transforma a explicação da deficiência como problema anátomo-fisiológico, portanto, não mais ligado ao campo teológico e moral. (PICCOLO; MENDES, 2012, p. 37-38).

Origina-se o predeterminismo da deficiência; as causas biológicas são a fonte. Sob essa ótica, a deficiência é imutável e o meio nada pode ofertar para reverter essa condição, conceito fundamental do inatismo que vigorava naquele tempo.

A educação especial surge no final do séc. XVIII e início do séc. XIX com um caráter altamente segregador de atendimento em entidades especializadas. "A sociedade toma consciência da necessidade de atender essas pessoas, mais com caráter assistencial do que educativo" (CARDOSO, 2004, p. 17).

Um marco histórico destaca o início da construção de uma concepção de reabilitação da deficiência: os estudos de Jean Itard, no ano de 1797, com o Selvagem de Aveyron. Assim, rompe-se com os ideais inatistas de incurabilidade e incapacidade e passa a vigorar uma concepçáo empirista de deficiência, onde as experiências com o meio são sensíveis e necessárias ao desenvolvimento da pessoa com deficiência.

A deficiência intelectual, percebida como patologia, estava sob a responsabilidade da área médica, que prescrevia as terapias. Não se cogitava qualquer tentativa de 
caráter educacional. Iniciou-se uma evolução com Edward Seguin, médico e aluno de Itard, que desenvolveu um programa de reabilitação sensorial e motora. Acrescendo evoluçôes ao seu trabalho, Guggenbull obtém êxito com deficientes intelectuais através da:

combinação de tratamento médico e educacional, focalizando exercícios de treinamento sensorial. Outra importante educadora que contribuiu grandemente para a evolução da educação especial foi Maria Montessori, médica Italiana que aprimorou os processos de Itard e Seguin, desenvolvendo um programa de treinamento para crianças retardadas mentais nos internatos de Roma. (MAZZOTTA, 2001, p. 22).

Montessori, precursora da abordagem de ensino multissensorial, criou um método que buscava a harmonia entre corpo, estrutura psicológica e emocional. Esta abordagem previa o favorecimento da interação e a cooperação entre os alunos. Dessa forma, adentrando o século XX, surgem iniciativas importantes no campo educacional que possibilitaram transformaçôes e consequentes evoluçôes teóricas. Entretanto, ainda prevalece com muita força o caráter médico-científico. A descrição proposta por Mendes (1996, p. 120-127), destaca a evolução histórica da representação pública e científica contemporânea da deficiência em 3 fases, sendo:

PRIMEIRA FASE: O nascimento do estudo científico da DM em 1918. Construção das primeiras teorias sobre idiotia a partir da observação de características anátomo-fisiológicas de adolescentes e adultos institucionalizados.

SEGUNDA FASE: Expansão do estudo por Binet (1908), atribui níveis de incapacidade, utiliza o termo debilidade mental, baseavase em atributos negativos das capacidades que eram ausentes.

TERCEIRA FASE: A partir da década de 30, questionam-se os pressupostos de organicidade patológica e de incurabilidade. Em 1959, Heber inclui uma definição sócio educacional além da tradicional classificação etiológica. Até meados do séc. XX, não foram observadas grandes evoluçóes, a concepção organicista ainda prevalece. A partir da década de 60 ocorre uma evoluçáo maior na metodologia do ensino especial com as abordagens comportamentalista e a abordagem cognitivista e desenvolvimentista.

A análise dessas fases possibilitará traçar elementos da gênese de uma forte tendência na educação especial: a compreensão médica do conceito de deficiência que engendra uma forma de trabalho que figura na patologização (Pessotti,1984; Bianchetti, 1998), que determina uma forma de trabalho pedagógico visando atingir um nível de normalidade estabelecido, revelando as dualidades tão discutidas como anormalidade-normalidade, deficiência-eficiência, incompetência-competência, inferioridade-superioridade. Essa normalidade é afirmada pelos testes de QI que mensuram os níveis intelectuais indicando o nível de desvio do padrão no âmbito acadêmico e 
de adaptação à vida social. Sobre os processos diagnósticos médico ou psicológico, Bridi e Baptista refletem que:

Quando produzidos a partir da medicina, referem concepçóes organicistas de deficiência, com ênfase na dimensão biológica associada à etiologia. Quando produzidos a partir da psicologia, caracterizam-se por serem diagnósticos psicométricos. Ambos os caminhos diagnósticos geram prognósticos muito fechados; são mapas restritos e previsíveis sobre os sujeitos, com pouco espaço para a surpresa e para o novo e, nessa medida, produzem o estático, a impossibilidade do vir a ser. (BRIDI; BAPTISTA, 2014, p. 501).

Buscando romper com a medicalização no conceito e nas açóes pedagógicas uma nova corrente configura um trabalho que oriente os procedimentos sobre os aspectos qualitativos considerando a constituição diferente do ser, reconhecendo as peculiaridades e características. "O sujeito é constituinte e não constituído", como diriam Osório e Leão (2014, p. 693). Nesta ótica propóe-se a exclusão da ideia de inferioridade e a aplicação da semântica da singularidade.

Este constructo histórico e a materialidade dos textos publicitários permitirão interpretar os sentidos que permanecem, que são significados, silenciados ou deslocados, a fim de compreender as imagens de DI que estes discursos constroem assentando as diferentes vozes que neles ecoam.

\section{Sujeito com deficiência nas tramas do discurso}

Neste trajeto analítico, será explicitado o entrecruzamento discursivo dos aspectos sociais, históricos e ideológicos envolvidos na construção da concepção de deficiência, considerando o espaço sócio histórico de produção; o lugar ocupado pelo DI na sociedade em cada momento relatado e as principais inscriçóes sócio ideológicas presentes. Será possível dar visibilidade ao fato de que os sujeitos do discurso fazem suas escolhas lexicais e imagéticas conforme as condiçôes de produção do discurso, essas que são a base dos processos discursivos, constituídas pelas relaçôes sociais em meio às quais os sujeitos históricos formulam seus dizeres. 


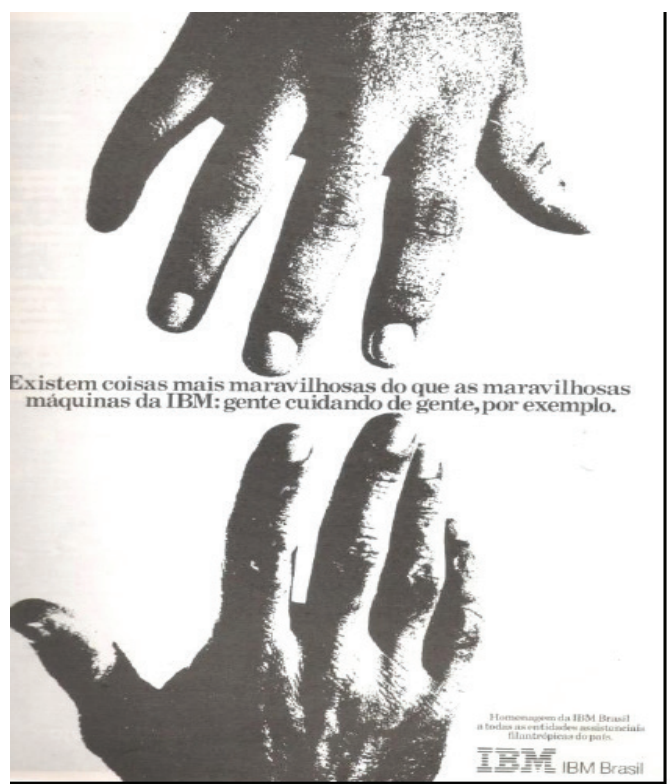

Figura1: PP IBM Brasil

Fonte: Revista Mensagem Ano 13 N. 40

Observando a imagem da Peça Publicitária1 (PP daqui para frente), podemos atentar para o fato de que há uma relação intertextual e interdiscursiva com uma imagem cristalizada no nosso imaginário: as duas mãos em destaque remetem, via memória, ao gigantesco afresco de Michelangelo na Capela Sistina, que representa uma cena da criação de Adão. Essa famosa obra apresenta uma contraposição entre homem e Deus, ou seja, uma oposição entre criador e criatura, um desnível, uma sobreposição. Na materialidade da PP1, atualizam-se esses sentidos ao mostrar mãos que igualmente convocam a contraposição: a relação entre a pessoa com deficiência e seus protetores. A máo que está sobreposta aponta para certo poder-autoridade, atribuída a um sujeito que ocupa um lugar discursivo de quem é preparado e capaz de cuidar daquele que é portador de uma deficiência, pictograficamente materializado por uma relaçáo de altivez, de soberania sobre o outro que lhe suplica ajuda.

A afirmação da atitude "cuidar de gente" como sendo algo que suplanta a magnitude de uma máquina de escrever e merecedora de homenagens inscreve socialmente as instituiçóes de educação especial em um lugar de benemerência e nobreza, posicionando o sujeito com deficiência num lugar sócio-ideologicamente constituído pela dependência e subordinação aos cuidados das instituiçóes especializadas.

Em uma marcha evolutiva na construção social do conceito de deficiência, surgem as teses da organicidade; deixam-se as ideias de vitimização e da ação das forças sobrenaturais para compreendê-las como consequência de uma patologia biológica, emergindo daí os discursos que promovem uma concepção médica-classificatória da deficiência. 
A PP2 destaca uma palavra utilizada como classificação da DI, em voga nos anos 80 , que surgiu em substituição aos termos altamente pejorativos utilizados anteriormente:

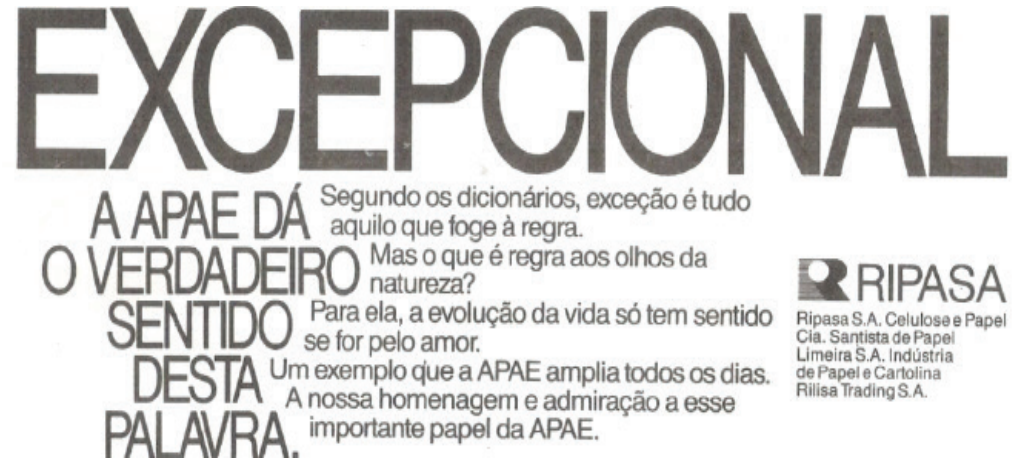

Figura 2: PP Ripasa Fonte: Revista Mensagem Ano 13 N. 40

Coloca-se em discurso a concepçấo de um sujeito com DI entendido como "excepcional". Busca-se silenciar a concepçáo classificatória e negativa que a palavra evoca, deslocando para um sentido sinônimo, salientando excepcional como aquele que foge a regra, relacionando-o com a evolução da vida. Assim, para o sujeito enunciador, essa evolução da vida só tem razão se for pelo amor. A rede interdiscursiva que envolve essa PP recita discursos que apregoam a benevolência.

Em um jogo de palavras com o termo papel, que é também o produto do fabricante enunciador, destaca-se a relevância e admiração da importante função de ofertar amor ao DI. Têm-se, assim, repetiçóes articuladas em um novo suporte, mas que guardam em si traços e vestígios da memória enraizada na história e na cultura sobre as bases caritativas do cristianismo.

$\mathrm{Na}$ esteira dos deslocamentos que promovem diferentes modos de conceber o sujeito com deficiência, a PP 2 está investida de sentidos implícitos que idealizam a deficiência pelos veios da medicalização e classificação; ecoam dizeres daqueles que caracterizam o trabalho com o DI como missionário e envolto em uma aura de bondade. Pelo reencontro da memória, tem-se a recorrência e a repetição revitalizadas, o que provoca, segundo Pêcheux (1999). uma negociação entre o choque do acontecimento histórico e o dispositivo complexo de uma memória que está na base dos dizeres e imagens.

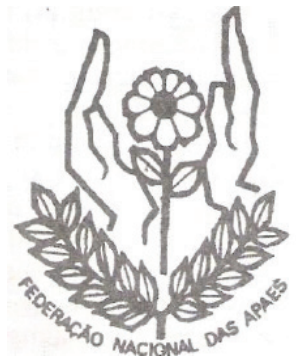

\section{A MÃO QUE AFAGA É A} MESMA QUE ORIENTA, ENSINA E GUIA, EM INCANSÁVEL MISSÃO DE TERNURA E AMOR.

Figura 3: PP Federaçấo Nacional das APAE's

Fonte: Revista Mensagem Ano XIV N. 46 
A PP 3 propõe a divulgação da Federação Nacional das APAE's, utilizando como mote as concepçôes filosóficas que circundam o símbolo da APAE. As mãos representadas indicam as pessoas que fazem parte dessa associação, ou seja, pais e amigos. Ao centro, resguardado por mãos que protegem e orientam, encontra-se o deficiente intelectual representado simbolicamente por uma margarida branca. Discursivamente, percebe-se uma tentativa de deslocamentos dos sentidos produzidos anteriormente. A mesma mão que afaga e cuida pode também apresentar um caráter de educador que orienta e guia. No entanto, resgata-se a memória da visão caritativa no atendimento ao deficiente intelectual. De modo semelhante, em virtude da dificuldade que a maioria das pessoas apresentam no trato com a diferença, aqueles que atuam nas escolas especiais são venerados e admirados, tal como os missionários. Isso traz à baila o discurso religioso das funçôes que deveriam ser profissionais e educacionais.

\section{Cumpra-se a Lei}
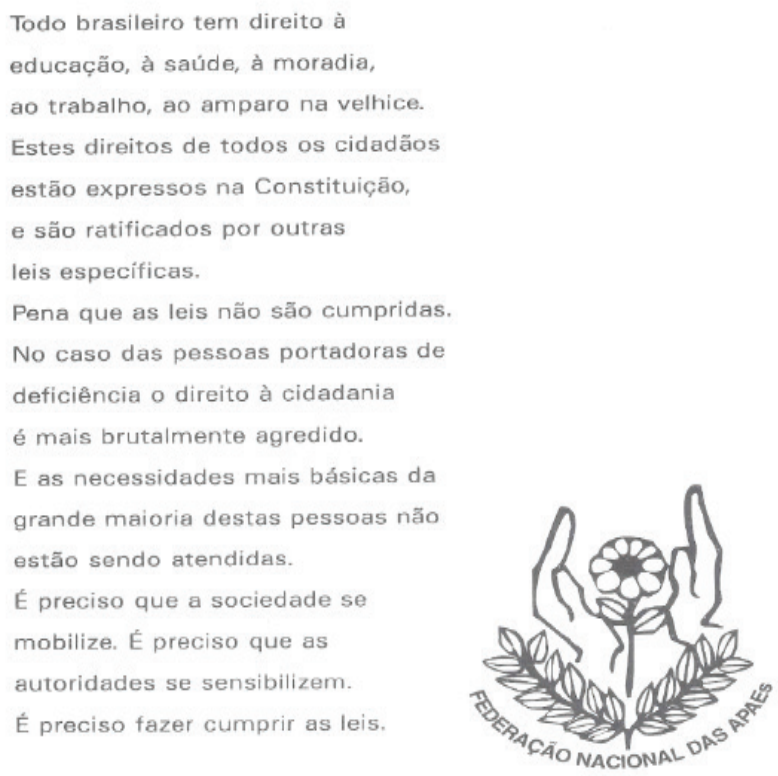

Cumpra-se a lei

Campanha de conscientização da FEDERAÇÃO NACIONAL DAS APAEs

Figura 4: PP Federação Nacional das APAE's

Fonte: Revista Mensagem Ano XXI n. 77

A partir dos anos 90, frente às discussões promovidas por encontros internacionais de inclusão social e educacional. somado a debates sobre cidadania motivados pela promulgação da nova constituição federal, ocorre um novo deslocamento em funçẫo das novas condições de produção do discurso. Emergem propagandas que não 
centralizam mais o amor, doação e missão. $\mathrm{O}$ texto da $\mathrm{PP} 4$ chama a atenção para um tema que extrapola o humanitário: o funcionamento da sociedade e os direitos dos cidadãos.

A comunidade e o governo não priorizavam a questão da pessoa com deficiência, pois estas preocupaçóes cabiam unicamente às instituiçóes. As pressóes por igualdade de direitos iniciam um debate solicitando uma mobilização da comunidade e a sensibilizaçáo do poder público frente a um descaso cristalizado pelo governo. No entanto, novamente se apela, no discurso, para a sensibilidade, referendando a diferença. $\mathrm{O}$ texto descreve que os direitos de muitos náo são respeitados, entretanto, os direitos dos deficientes são inferiormente atendidos.

Analisando uma propaganda que circulou no ano de 2009 , é possível traçar um paralelo com as anteriores e perceber os silenciamentos, estabilizaçóes dos sentidos e outros efeitos do interdiscurso na construçáo de imagens do DI.

A PP 5, publicada em uma edição de 2009 da Revista Mensagem, permite comparar a diferença de concepçôes. O texto principal realiza um jogo de sentidos com a palavra presente, considerando que a APAE, com o seu atendimento, é capaz de ofertar a seus alunos um excelente futuro. A imagem revela um aluno da APAE incluso no contexto educacional, rodeado por elementos que cercam o ambiente escolar. $\mathrm{O}$ texto marca fortemente o caráter educacional, a defesa de direitos, a especialidade dos profissionais que atuam com o deficiente intelectual e a experiência acumulada.

O discurso que revela a aptidão educacional das APAE's e a sua capacidade de colaboração com o processo de inclusão, aspecto que foi silenciado pelo forte caráter assistencialista imbricado no inconsciente e na memória discursiva dos sujeitos enunciadores e leitores. 


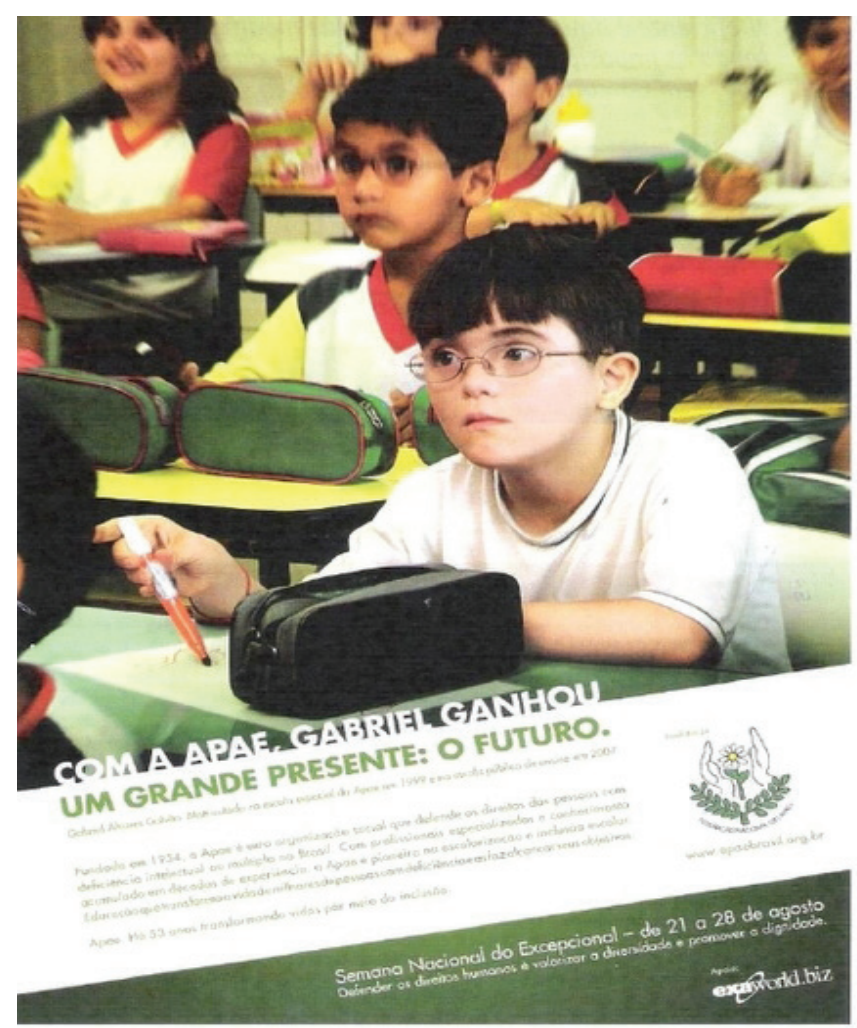

A Semana Nacional foi revigorada em 2005, após a Declaraçāo

da Organizaçāo dos Estados Americanos (OEA), em que estabeleceu a "Década das Américas: pelos Direitos e pela Dignidade das

Pessoas com Deficiência, durante o período 2006-2016", elegendo como lema: "lgualdade, Dignidade e Participąão".

A Federação Nacional das Apaes adotou este lema para os próximos dez anos - Igualdade, Dignidade e Participaçâo-que tem pau. tado todas as suas açōes desde então. Em 2008 não foi differente.

Figura 5: PP Federação Nacional das APAE’s. Fonte: Revista Mensagem Ano 41 N. 97

A PP 6 faz parte de uma campanha amplamente realizada pelas APAE's do Estado do Paraná, com a finalidade de arrecadar recursos. Recupera, interdiscursivamente, um poema de Fernando Pessoa que rememora um texto bíblico. Ocorre aqui um rompimento com o discurso inclusor proposto na propaganda anterior, havendo uma dispersão de sentidos que retoma o discurso missionário do amor como centro das açôes das Escolas Especiais. Mais uma vez, observa-se o que ensinou Pêcheux (1988): toda formulação discursiva convoca outras formulações que falam antes, em outro lugar, independentemente. A memória discursiva funciona, nessa PP, requisitando que os discursos e as palavras já tenham sentidos na rede de memória que salienta o caráter de benevolência e de amor presentes nas instituiçóes. 


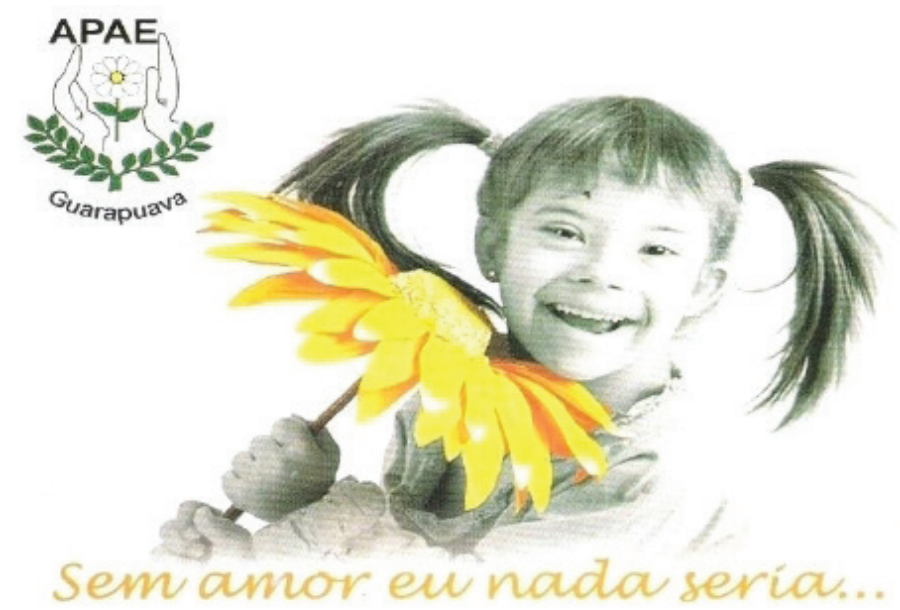

... e na APAE temos muito mais que amor!

Você nem imagina o quanto a APAE de Guarapuava melhora a vida de pessoas especiais.

Escute o que temos a Ihe falar, participe da campanha "APAE - Um gesto de AMOR"

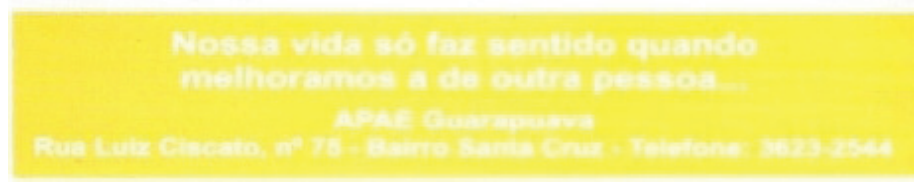

Figura 6: PP central de arrecadação de recursos. Fonte: Fedapaes

Ao afirmar que, na APAE, oferece-se mais do que amor, ficam implícitas as outras importantes açôes, mas estas não são reveladas, prevalecendo a manutenção de uma posição sócio-ideológica de total dependência e subordinação aos cuidados da escola especial. Ocorre aqui um entrecruzamento com a produção de discursos que pareciam já estar superados, mas que a necessidade de arrecadação de fundos fez rememorar, fazendo, assim, coexistirem discursos divergentes sobre a concepçáo da deficiência na atualidade.

Analisadas em seu conjunto, as peças selecionadas, no movimento de descrição-interpretação, estão enredadas em tramas discursivas, constituídas por redes de memórias, que permitem dar visibilidade a certos trajetos sociais dos sentidos que fala do sujeito com deficiência. Na heterogeneidade, demos destaque para o "discurso outro, enquanto presença virtual na materialidade descritível da sequência, [marcando] do interior dessa materialidade a insistência do outro como lei do espaço social e da memória histórica, logo como o próprio princípio do real sócio-histórico" (PÊCHEUX, 2006, p. 53). 


\section{Considerações finais}

Retomando Maldidier (2003, p. 96), "o sujeito não é fonte do sentido; o sentido se forma na história através do trabalho da memória, a incessante retomada do já-dito; o sentido pode ser cercado, ele escapa sempre". Justamente porque há sempre um discurso, a memória discursiva é considerada como condição necessária para a emergência e circulação de todo e qualquer discurso. Foi à luz desse pressuposto que foram analisadas as peças publicitárias produzidas em diferentes momentos e, portanto, por diferentes sujeitos discursivos, notadamente entre os anos de 1980 a 2009.

Sob o crivo do discursivo, visualizaram-se as transformaçôes que a história produziu nas concepçóes sobre o sujeito com deficiência: de um modelo beneficente/ assistencialista, desloca-se para um modelo médico/terapêutico, tentando-se, enfim, ensaiar um modelo educacional inclusivo, mas, como salientam Osório e Leão (2013, p. 687-688), com marcas da integração, já que a maioria das escolas apresentam marcas do modelo clínico.

A maioria das propagandas trata da atuação das instituiçóes como obra missionária, embasada no amor ao deficiente intelectual ou na classificação tipológica da deficiência que tende a classificar, mensurar e traçar parâmetros entre o que é normal ou anormal, de acordo com os ideais positivistas. Ao sair das mãos da caridade, a ciência assume o centro da vida da pessoa com deficiência. Ocorre, dessa forma, um assujeitamento aos diagnósticos e decisōes dos profissionais da saúde, causando uma diminuição do caráter pedagógico, visto que poucas propagandas salientam o aspecto educacional presente nas escolas de educação especial mantidas por instituições privadas.

A patologização da deficiência pode carregar um sentido de inadaptação, gerando expectativas negativas através de classificaçōes marginalizantes, que mantém a segregação e os padrōes de inadaptação, aliás, o simples ato de definir carrega questóes conceituais para reflexão. Conforme alertam Santos; Mendonça e Oliveira (2014), as práticas classificatórias levam a "homogeneização dos grupos de alunos, das práticas pedagógicas, além de estabelecer limites ao desenvolvimento intelectual dos mesmos".

As diferentes mídias vêm sendo acionadas para a constituição de um imaginário social condizente com as representaçôes da filosofia sócio-antropológica de deficiência, no entanto, os atravessamentos impedem as representações da inclusão. Esses atravessamentos são revelados nas contradiçôes dos discursos das propagandas atuais que, na tentativa de internalização de papéis voltados à inclusão, deixam-se influenciar por paradigmas ultrapassados. Isto ocorre porque as instituições, por sua natureza filantrópica, necessitam do apoio da sociedade civil para a sua manutenção, apelando para discursos que recorrem à emoção.

A Deficiência Intelectual é um conceito manipulado ao longo do tempo e que tem sido construído à imagem e semelhança daquelas edificadas pelas entidades filantrópicas. Por muito tempo, toda e qualquer referência ao assunto dependeu de suas iniciativas. Dessa forma, os discursos reveladores das instituiçôes poderiam mudar de orientação, centrando-se na observação de direitos, iniciativas de manifestação da 
individualidade, foco na diversidade, no apoio à construção da autonomia de decisão do aluno e, principalmente, na divulgaçáo premente do caráter educacional.

Ao reavaliar suas posiçôes conceituais, as instituiçôes poderiam vislumbrar um tempo de educaçáo plena, organizada e significativa ao aluno, sem os entraves impostos pela caridade, protecionismo, benevolência e classificação organicista.

\section{Referências}

BIANCHETTI, L. Aspectos históricos da apreensão e da educação dos considerados deficientes. In: BIANCHETTI, L.; FREIRE, I. M. (Orgs.). Um olhar sobre a diferença: interação, trabalho e cidadania. 4. ed., Campinas: Papirus, 1998, p. 21-51.

BRIDI, F. R. S; C. R. BAPTISTA. Deficiência mental: o que dizem os manuais diagnósticos? Revista Educaçáo Especial, Santa Maria, v. 27, n. 49, p. 499-512, maio/ago., 2014. Disponível em: <http://www.ufsm.br/ revistaeducacaoespecial>. Acesso em: 29 set. 2014.

CARDOSO, M. S. Aspectos históricos da educação especial: da exclusão à inclusão-uma longa caminhada. In: STOBÄUS, C. D. Educaçáo Especial: em direção à educação inclusiva. Porto Alegre, Edipucrs, 2004.

CECCIM, R. B. Exclusão e alteridade: de uma nota de imprensa a uma nota sobre a deficiência mental. In: SKLIAR, C. (Org.). Educaçáo \& Exclusão: abordagens sócio-antropológicas em educação especial. Porto Alegre: Mediação, 1997.

MALDIDIER, D. A inquietaçáo do discurso: (re)ler Michel Pêcheux hoje. Campinas: Pontes, 2003.

MAZZOTTA, M. J. S. Educaçáo especial no Brasil: história e políticas públicas. São Paulo: Cortez, 2001.

MENDES, E. G. Evoluçáo histórica da concepção científica de deficiência mental. Temas em educação especial vol. 3. São Carlos: EDUFScar, 1996. 580 p.

ORLANDI, E. P. Análise do discurso: princípios e procedimentos. Campinas: Pontes, 1999.

OSÓRIO, A. C. N.; LEÃO, T. C. L. Diversidade e educaçấo especial em diálogos: reflexóes sobre os discursos da inclusăo. Revista Educaçáo Especial, Santa Maria, v. 26, n. 47, p. 685-698, set./dez. 2013. Disponível em: <http://www.ufsm.br/revistaeducacaoespecial>. Acesso em: 29 set. 2014.

PECHÊUX, M. Papel da memória. Campinas: Pontes, 1999.

. Semântica e discurso: uma crítica à afirmação do óbvio. Campinas: Editora da Unicamp, 1988.

. O discurso: estrutura ou acontecimento. 4. ed. Campinas: Pontes, 2006.

. Especificidade de uma disciplina de interpretação. In: PIOVEZANI, C.; SARGENTINI, V. Legados

de Michel Pêcheux inéditos em Análise do Discurso. São Paulo: Contexto, 2011.

PESSOTTI, I. Deficiência Mental: da superstição à ciência. São Paulo: T. A. Queiroz, 1984.

PICCOLO, G. M.; MENDES, E. G. Nas pegadas da história: tracejando relações entre deficiência e sociedade. Revista Educaçáo Especial, Santa Maria, v. 25, n. 42, p. 29-42, jan./abr. 2012. Disponível em: <http://www. ufsm.br/revistaeducacaoespecial>. Acesso em: 29 set. 2014.

RIBEIRO, M. L. S. Perspectiva da escola inclusiva: algumas reflexôes. São Paulo: Avercamp, 2003.

SANTOS, R. A.; MENDONÇA, S. R.; OLIVEIRA, M. C. A instituição especializada em tempos de inclusão. Revista Educaçáo Especial. Santa Maria, v. 27, n. 48, p. 41-52, jan./abr., 2014. Disponível em: <http://www. ufsm.br/revistaeducacaoespecial>. Acesso em: 29 set. 2014.

\section{Correspondência}

Carla Maria de Schipper - Rua Luiz Ciscato, 75, Santa Cruz. CEP: 85015-070 - Guarapuava, Paraná - Brasil.

E-mail: carlaschipper@gmail.com - denisewitzel@uol.com.br

Recebido em 29 de outubro de 2014

Aprovado em 9 de março de 2015 